\title{
Imaging spectroscopy and integrated coastal zone management: a promising marriage
}

\author{
B. Deronde, S. Sterckx, L. Bertels, E. Knaeps \& P. Kempeneers \\ Flemish Institute for Technological Research (VITO), \\ Remote Sensing and Earth Observation Processes, Boeretang, Belgium
}

\begin{abstract}
This paper provides an overview of the coastal and marine applications which make use of Imaging Spectroscopy (IS), recently under development in Vito. It should be considered as a concise overview rather than an in depth presentation of one application or development. The first two applications focus on sediment mapping; firstly, a classification of sediment habitat types of the Molenplaat, a tidal sand bank in the Westerschelde, is presented. By means of feature selection and a supervised binary classification approach the sediment is classified according to its grain size, moisture content, organic matter content and chlorophyll-a concentration. The second application uses airborne IS to classify the different sand types present along the Belgian coast, in combination with airborne laserscanning to derive accurate erosion maps. The combination of both data products results in a method which proves to be very suited to monitoring the sand transport processes along the Belgian coast. Afterwards two aquatic applications are presented; in the first, coral reef communities in Indonesia are classified. Extensive field work served to collect a spectral library which is used to classify the coral reef communities in as much detail and as accurately as possible. The second aquatic application addresses the difficult challenge of quantifying the amount of suspended sediment and chlorophyll-a in water and rivers; this is performed by inversion of a bio-optical model using a set of Specific Inherent Optical Properties (SIOP's) measured in-situ. Many marine applications ask for some specific processing steps which are inherent to the aquatic environment. Therefore the last study in this overview focuses on the atmospheric correction above water bodies. Due to the high absorption and transmission of water bodies the reflected radiation level is low compared to land. To extract this small signal from a much greater base of other radiance a very accurate atmospheric correction algorithm is required. Therefore a specific atmospheric correction algorithm, WATCOR, has been developed to account for the marine atmospheric conditions as well as for the air-water interface.
\end{abstract}




\section{Introduction}

Imaging spectroscopy is an innovative remote sensing technique which can be defined as the acquisition of images in hundreds of registered, contiguous spectral bands such that for each picture element of an image it is possible to derive a complete reflectance spectrum (Goetz [6]). The high spatial and spectral resolution of imaging spectrometers offer the opportunity to study the Earth's surface in more detail than conventional multispectral remote sensing techniques offer. This paper focuses on the applications of imaging spectroscopy in coastal areas. The economic and social importance of the coastal zone as well as the challenges for the application of remote sensing in these areas are described by Cracknell [3]. The paper should not be considered as an in-depth presentation of one particular study but rather as an overview of a few applications of imaging spectroscopy in coastal zone studies. The first two applications focus on the mapping of sediments: in the first one sandy beaches are classified according to different sand types and the sand transport is quantified, while in the second application a tidal sand bank is classified according to its grain size, moisture content, organic matter content and chlorophyll a concentration. Afterwards two aquatic applications are presented: in the first, coral reef communities in Indonesia are classified while the second deals with the quantification of the amount of suspended sediment and chlorophyll-a in water and rivers. The last chapter is reserved for the atmospheric correction over water bodies; this is a methodological application which is needed in the processing of hyperspectral data for aquatic applications.

\section{Applications}

\subsection{Mapping of sediment habitat types on the Molenplaat (Westerschelde)}

\subsubsection{Introduction}

The Westerschelde estuary is home for one of the largest wading bird populations in western Europe. Several rare habitat types such as freshwater tidal marshes make the Schelde estuary a site of international recognition and importance for nature. But the estuary is also a site of heavy industry, and it is an important commercial shipping transport route. Coastal zone managers must constantly balance the demands of many conflicting interest groups when making planning decisions which affect this complex system. Decision making can be improved if better knowledge of ecological processes is available. Many of the most important bio-geochemical processes occur on the large areas of soft sediments which are exposed at low tide. This study focuses on the use of imaging spectroscopy for the mapping of sediment habitat types in these areas. A supervised binary classification approach based on feature selection and linear discriminant analysis is adopted to classify the median grain size, the moisture content, the total organic matter content and the chlorophyll-a concentration.

The detailed description of this research can be found in Deronde et al. [5], submitted. 


\subsubsection{Results}

In this paper the results of the classification of the median grain size are presented. Table 1 lists the overall accuracies, after classification of the training samples, for each optimal band set. It can be seen that the accuracy rises in an pseudo-asymptotic way when selecting more bands, i.e. when only one band can be used, the highest possible accuracy is $63 \%$ (when using the most suited band), in case of two bands $79 \%$ etc. Using more than 4 bands does not result in higher accuracies.

Table 1: Classification accuracies of the median grain size for different band sets.

\begin{tabular}{|l|l|}
\hline$\#$ of bands & Overall accuracy \\
\hline 1 & $63 \%$ \\
\hline 2 & $79 \%$ \\
\hline 3 & $84 \%$ \\
\hline 4 & $86 \%$ \\
\hline 5 & $86 \%$ \\
\hline 6 & $86 \%$ \\
\hline
\end{tabular}

A feature selection algorithm served to define the bands which are most suited to classify the sandy sediments according to its median grain size. It was found that the bands in the VNIR range led to the highest classification accuracies. Especially wavelengths 466, 497, 558, 619, 665, 846, and 862 were often selected for classification. The classification of the image was performed with four bands. The classified map is shown in Figure 1. The yellow zones indicate areas with (mostly fine) sand $(125-250 \mu \mathrm{m})$. This fraction is found in a large area in the middle of the plate and on the south-western part of the plate which is quite elevated (indicated as regions I and II). In the eastern part it is found in combination with the loamy sand class. Note the mega-ripples in this part of the scene (III); the top of the ripples is characterized by sand while loamy sand occurs in the valleys. The yellow class is also found in the bed of small runoff channels in the north of the scene (IV), while finer classes occur around the channels. This can easily be explained by the higher current velocities and shear stress within the run-off channels. The finest class, clayey loam, is found in the large central part of the scene and in an area in the west ( $\mathrm{V}$ en VI). Another remarkable feature on the classified image is the difference between the eastern and western part of the Molenplaat. The black dashed line indicates the border between both entities. The sedimentological differences make it likely that the actual Molenplaat originated from two separate banks. This assumption is strengthened by the fact that recent shipping maps refer to the Brouwersplaat for the western part and to the Molenplaat for the eastern part of the actual Molenplaat. The historical maps of the hydrographical unit of the harbour of 
Antwerp show clearly that between 1930 and 1935 the old Molenplaat and the Brouwersplaat merged into the actual Molenplaat, although at that time there was still a tidal gully between both plates. In the forties the gully disappeared and both plates were joined. It is an interesting conclusion that remote sensing images show signs of this history.

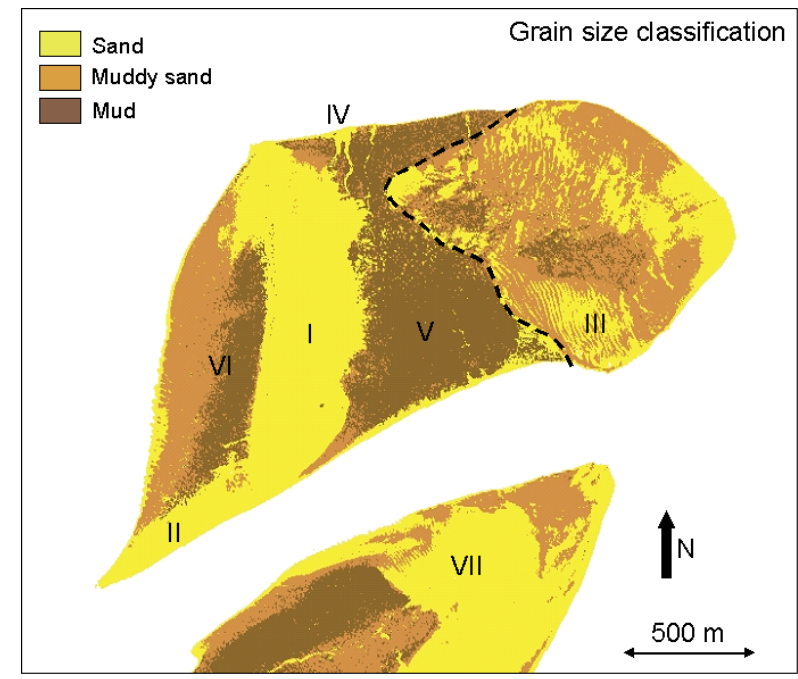

Figure 1: Classified image of the Molenplaat indicating three grain size classes: sand, loamy sand and clayey loam.

Similar analyses were performed for the three other parameters studied. As little as 3 to 5 bands were required to classify each of these parameters with the highest possible accuracy. The bands were most often selected in the VNIR part of the spectrum. The SWIR bands were barely used in the classifications what implies that for this application it is probably sufficient to use a more common VNIR sensor. The overall accuracy is highest for the total organic matter content $(87 \%)$ and the median grain size $(86 \%)$. The moisture content and the Chlorophyll-a content score somewhat lower with $81 \%$ and $80 \%$ respectively.

\subsection{Monitoring of sand transport processes along the Belgian coast}

\subsubsection{Introduction}

The Belgian Coast stretches for about $65 \mathrm{~km}$ between De Panne in the Southwest and Knokke-Heist in the Northeast. From a geological point of view, this coastline is part of the 'Flemish coastal plain', a depositional system at the southern edge of the North Sea Basin which is commonly known as the Southern Bight. Since the beach is of major economic importance to Belgium and since it is part of the natural defense protecting the polders against flooding, it is very important to obtain a better understanding of the processes that control the beach. In the study presented airborne hyperspectral data and airborne LIDAR data have 
been used to study the sand transport processes controlling the morphology of the beach. The detailed description of this study can be found in Deronde et al. [4] (in press). In August 2000, August 2001 and October 2002 airborne hyperspectral data were acquired over the Belgian coast. All data were recorded with a CASI-2 sensor measuring the reflected sunlight in a $545 \mathrm{~nm}$ spectral range (410-955nm). A supervised SAM (Spectral Angle Mapper) algorithm was applied to classify the images.

Almost simultaneously to the hyperspectral campaigns, an airborne laserscanner was deployed. The distance to the Earth's surface is determined by measuring the laser pulse return time. The position and attitude of the sensor is calculated from d-GPS and INS (Inertial Navigation System) data. In combination with the scan angle, the 3D position of each laser beam spot on the surface can be determined, resulting in DTMs with a vertical accuracy of $5 \mathrm{~cm}$. By subtracting the DTMs from consecutive years maps indicating the erosion/accretion zones could be extracted.

The combination of the erosion/accretion maps and the classifications derived from the hyperspectral data, generated a product which is well suited to follow up the sand transport processes which are responsible for the beach morphology.

\subsubsection{Results}

Figure 2 illustrates a classification of the beach near Zeebrugge; in the west the image is bounded by the pier of Blankenberge, in the east by the harbour of Zeebrugge. Eastward of the Pier of Blankenberge, a beach nourishment zone stands out. Between October 1998 and April 1999, nearly 500,000 $\mathrm{m}^{3}$ of sea sand were put on the backshore. The sea sand is coarser grained than the original sand, contains a large amount of shells and even some gravel. Because of its different composition, it can spectrally be distinguished from other types of sand what implies that, in this case, IS is very suited to follow up the soft defense structures along the Belgian coast. In total 8 sand classes were distinguished.

The classified sand maps were combined with the erosion/accretion maps. This resulted in a product that indicates the amount of erosion or accretion between two surveys, as well as a possible change in type of sand at the surface during that period. The classified sand map helps explaining the erosion/accretion maps, i.e. the classes serve as tracer. Figure 3 illustrates the sand dynamics map for the Knokke-Zoute area. Between March and May 1999 a beach nourishment with sea sand was performed from section 233 till section 243. On the seaward side of the nourishment area there is an important erosion zone of $31,800 \mathrm{~m}^{3}$ (area 17); the mean height difference here is $-49 \mathrm{~cm}$. However, the type of sand remains the same which means that the erosion is still limited to the nourished volume. In area 16 class 7 is replaced by class 5 indicating that the erosion reached the underlying sand type. In area 18 a small erosion strip replaced class 7 by class 3 and 4; these are typical sand types of the wet beach which means that there is probably a landward regression of the nourishment area. 


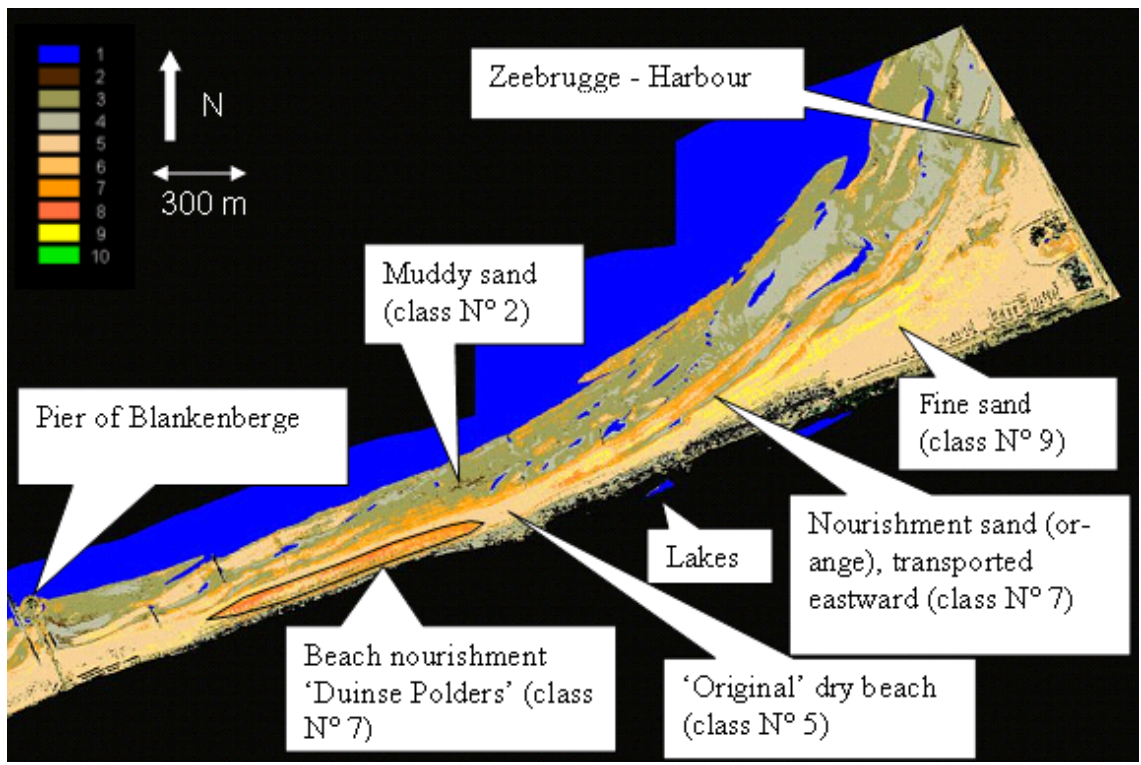

Figure 2: $\quad$ Classified image (2000 survey) of the beach between Blankenberge and Zeebrugge. Eight different sand types could be distinguished (labelled $2-9$ in the legend; class 1 is water and class 10 is vegetation).

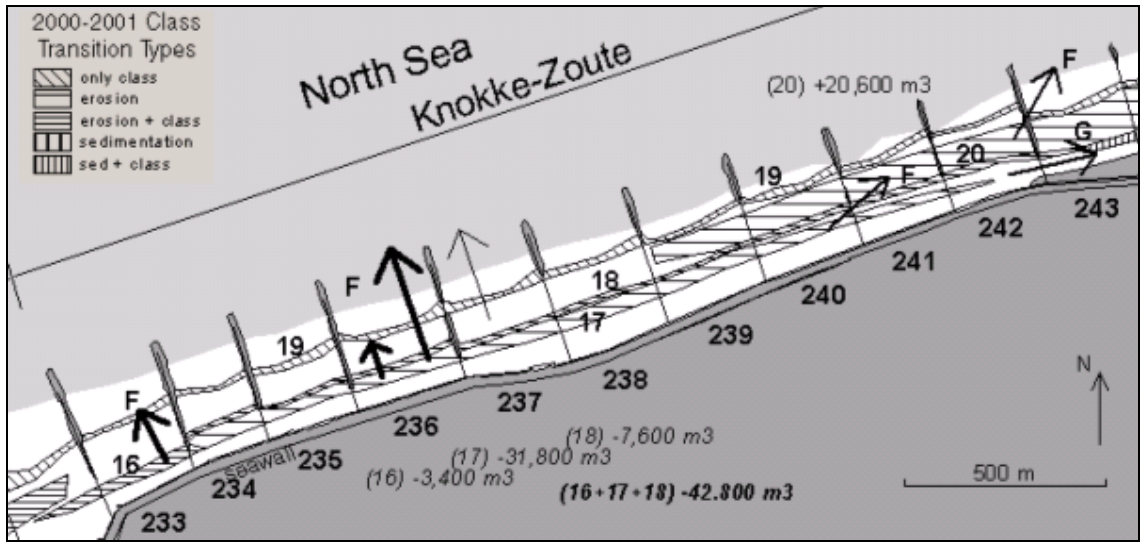

Figure 3: Schematical representation of the sand transport directions and volumes between 2000 and 2001 in Knokke-Zoute. The thickness of the arrows is an indication of the amount of sand transported: thick arrows indicate more sand transport than fine arrows ('erosion' = erosion without class change, 'sedimentation' = sedimentation without class change, 'erosion + class' $=$ erosion and change in class, 'sedimentation + class' $=$ sedimentation and change in class, 'only class' = change in class but no erosion or sedimentation). 
Similar analyses and maps have been made for the entire Belgian coast. They lead to more insight in the sand transport processes controlling the beach.

\subsection{Coral reef monitoring in Fordate, Tanimbar (Indonesia)}

\subsubsection{Introduction}

Coral reefs are considered to be one of the most spectacular marine ecosystems on earth displaying an extremely rich biodiversity. They also represent valuable socio-economic resources. Despite this natural wealth and socio-economic significance, many threats are posing stress on coral reefs. According to Bryant et al. [2] 58\% of the coral reefs in the world are potentially endangered by devastating human activities. The most important worldwide threats generated by human activities are pollution, sedimentation and unsustainable fishing activities (Bryant et al. [2], Spalding et al. [12]). Current coral reef monitoring techniques range from underwater transect monitoring to remote sensing data analysis (Bryant et al. [2]). Remote sensing data offer the opportunity to gather information over vaster areas compared to traditional 'on-the-spot' survey methods where only limited spatially distributed information can be collected. Remote sensing makes it also possible to follow up the situation in a multitemporal manner. In this way remotely sensed observations can help to monitor changes in coral reefs and to differentiate between anthropogenic and natural effects on coral reef health (Kutser et al. [9]). Most satellite data are well suited for coarse-level mapping of the geomorphology and bottom-type composition of the reefs. However, today, they are often lacking the spatial and/or the spectral resolution which is required to create detailed bottom-type maps and to detect and monitor the health status and vitality of coral reefs. Hyperspectral airborne sensors, on the other hand, have a high potential for not only mapping small coral reef ecosystems but also for identifying areas with bleached or stressed corals. Kutser et al. [9] recognise three main advantages of hyperspectral sensors: they possess a large number of narrowband channels capable of discriminating bottom-types in more detail (Mumby and Edwards [11]), their large number of bands increase the capacity to unmix spectral signatures (Hedley and Mumby [17]), and they can also distinguish bottom-types in deeper waters.

A feasibility study on Fordate, a small island to the Northeast of Tanimbar archipelago (South-East Moluccas, Eastern Indonesia), was undertaken to assess and verify the technical feasibility of a future-generation, spaceborne hyperspectral sensor. This preliminary study was based on the analysis and interpretation of experimental CHRIS/PROBA satellite imagery. A short overview of the results of this preliminary study is discussed below; more details can be found in Bertels et al. [1].

\subsubsection{Results}

A CHRIS/PROBA dataset was acquired over Fordate on 27 January 2004. The CHRIS instrument was programmed in its mode 2 (optimized for water applications), which contains 18 spectral bands and a full spatial resolution of 20 $\mathrm{m}$ at nadir. The atmospheric correction was performed with the in-house software WATCOR (see section 2.5). Since no actual field survey has been 
undertaken, the classification was based on image inherent information. Both spectral and spatial image information was used to select the endmembers automatically. After the endmember selection, all image pixels were compared to the endmembers using a Spectral Angle Mapper (SAM) procedure. SAM computes a spectral angle between each pixel spectrum and each endmember spectrum. The smaller the spectral angle, the more similarity between the pixel and target spectra is assumed. In this way a map of the bottom-types was created using the CHRIS/PROBA data. The result of the classification is shown in Figure 4. An attempt was made to assign names to the endmember classes. As no ground-truth information was available, this was based on the visual examination of the endmember reflectance spectra and a priori knowledge of the reef geomorphology. More detailed, supervised classifications, achieved after a water-column correction, will be produced in an ongoing research project (Bertels et al. [1]).

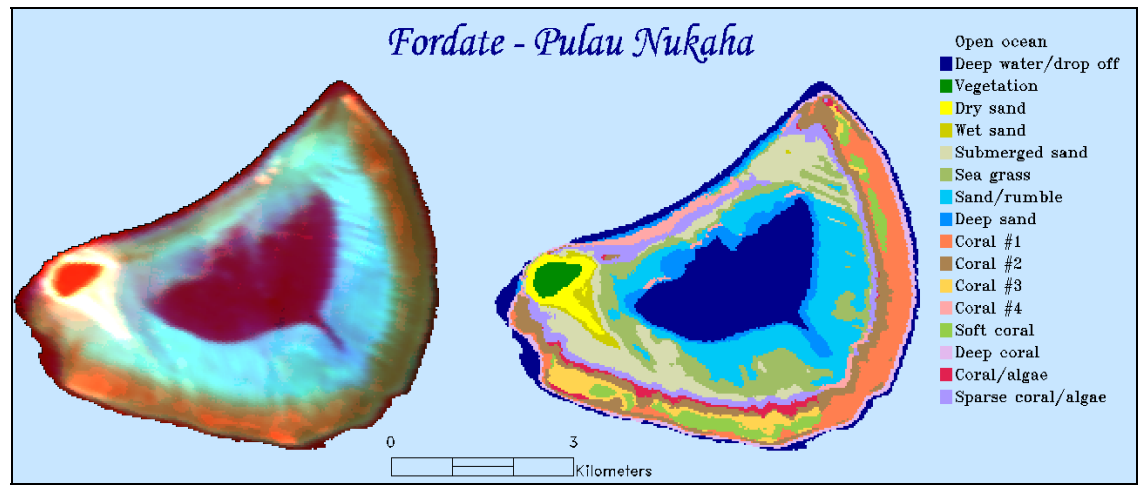

Figure 4: $\quad$ Preliminary Bottom-Type Classification based on CHRIS/PROBA Data over Pulau Nukaha, Fordate.

\subsection{Water quality monitoring}

\subsubsection{Introduction}

There exists a high interest in chlorophyll (CHL) and suspended particulate matter (SPM) maps of the Belgian coastal and estuarine waters. In the framework of the Oslo and Paris Commissions for the prevention of marine pollution (OSPARCOM) Belgium has to classify their coastal waters according to their eutrophication status. The eutrophication problems of the coastal waters results from an augmentation of anthropogenic nutrient inputs via the main rivers, the Atlantic waters and regional atmospheric deposition. Furthermore sustainable dredging is required to keep the ports of Zeebrugge and Antwerp accessible for large ships. The large quantities of dredged material are often dumped back into the sea. Besides the economic costs, dredging and dumping of dredged material can cause serious environmental problems. To optimize the dredging operations knowledge of the suspended sediment concentration is required. 
Water quality monitoring using hyperspectral airborne data is carried out by VITO in the framework of two projects: ORMES and BELCOLOUR. In ORMES a methodology is being developed to derive suspended sediment concentrations from the images; it will be robust, relatively insensitive to the sediment characteristics and applicable with a minimum of ground truth/calibration points. The BELCOLOUR project (http://www.mumm.ac.be/BELCOLOUR) brings together three Belgian teams (ULB,MUMM and VITO) to improve the theoretical basis and the software tools for applications of suspended particulate matter and chlorophyll products from remote sensing data of coastal waters.

In this paper we briefly look at the first results obtained in the ORMES project. In the framework of this project an AHS-160 hyperspectral airborne campaign took place over a test site following the Scheldt River in Belgium on the 15th of June 2005. Simultaneously to the airborne overpasses water samples were collected and field measurements of water leaving reflectance and turbidity were made.

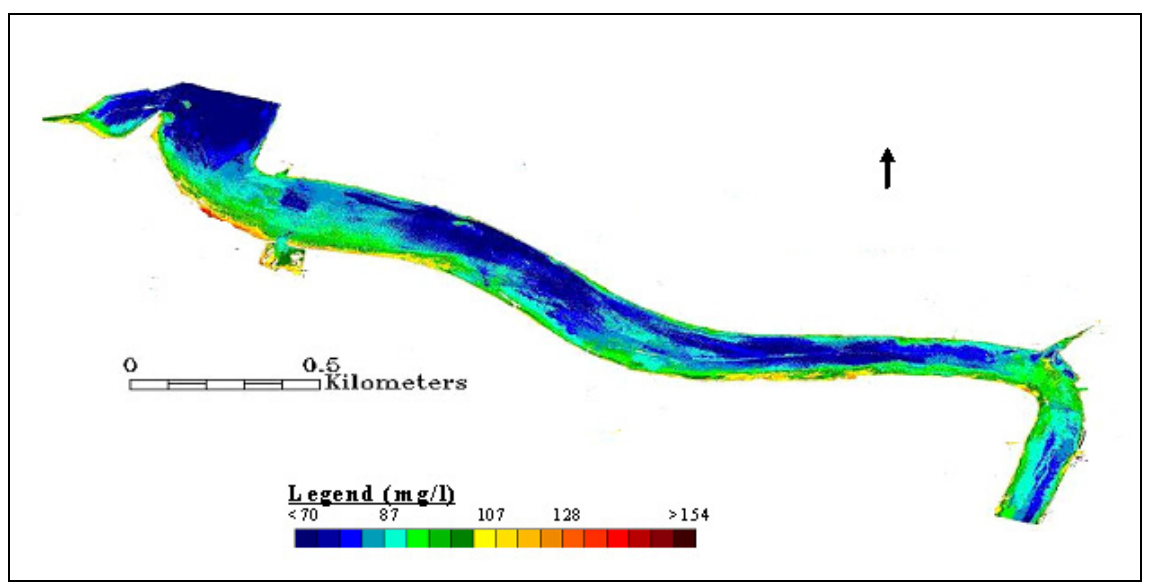

Figure 5: $\quad$ SPM concentrations ( $\mathrm{mg} / \mathrm{l})$ in the river Scheldt - 08:44h (UTC).

\subsubsection{Results}

The retrieval of suspended sediment concentrations from the AHS data was tested on the in situ reflectance measurements, resampled to the AHS bands using different empirical algorithms from the literature. The highest correlation coefficient between measured and calculated SPM concentrations (0.78) was obtained using the SPM algorithm of Matthews et al. [10]. This algorithm was used to obtain a first suspended sediment map of the Scheldt test site. Figures 5 and 6 show the preliminary results for an image taken at 08:44 UTC time and 11:13 UTC time respectively. On the day of the flight, the highest water level was measured at $08: 58 \mathrm{~h}$ UTC time. Hence, the image was taken close to the tidal maximum what explains the low current speed and the low concentrations of suspended sediment, as can be seen in figure 5. At 11.13h (Figure 6), the 
concentrations are clearly higher because the outgoing tide causes much higher current speeds. Note also that the highest sediment concentrations are found along the erosive outer banks of the river; lower concentrations can generally be found in the middle of the stream and at the sedimentary inner banks. The eroded material is taken in suspension and transported downstream. These processes are clearly visible in Figure 6.

The next goal is to modify the existing algorithms by using the image spectra instead of the in situ reflectance measurements. Linear and logarithmic relationships between in-situ SPM/turbidity and image reflectance will be tested and a hydro-optical model will be calibrated for this specific location.

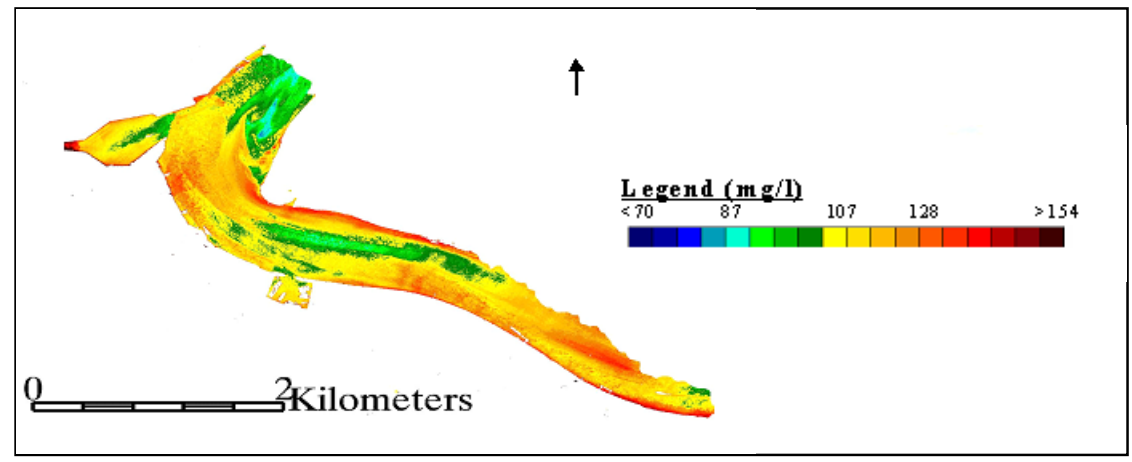

Figure 6: $\quad$ SPM concentrations (mg/l) in the river Scheldt - 11:13h (UTC).

\subsection{Atmospheric and air-interface correction above water bodies}

\subsubsection{Introduction}

Atmospheric correction is essential for adequate extraction of water quality information from remotely sensed data. The effect of scattering and absorption by the atmosphere can be substantial. Due to the high absorption and transmission of water bodies the reflected radiation level is low compared to land. To extract this small signal from the other radiance components such as path radiance, a very accurate atmospheric correction algorithm is required. Therefore a specific atmospheric correction, WATCOR, has been developed to account for the atmospheric conditions as well as the air-water interface (Sterckx and Debruyn [13]).

\subsubsection{Results}

The WATCOR algorithm was applied to CASI data acquired from the North Sea in the framework of the BELCOLOUR project (see section 2.4). To estimate the visibility during the time the CASI data were acquired two different approaches were evaluated. In the first methodology the visibility was estimated using MODTRAN-4 radiative transfer simulation combined with the sun photometer aerosol optical depth measurements. This procedure is similar to the approach given in (Keller [8]) and is based on the fact that at $550 \mathrm{~nm}$ the aerosol optical depth is independent of the aerosol type and atmospheric model but only varies 
with the visibility. The second method is an adapted dark target approach and assumes that there is a pixel in the deeper water regions for which the waterleaving radiance is negligible in the near-infrared. Detailed information can be found in Sterckx and Debruyn [13]. The first approach resulted in an average visibility of $+/-20 \mathrm{~km}$. The average visibility derived with the adapted dark target approach was a bit lower $+/-18.8 \mathrm{~km}$. Based on these results it was decided to set the visibility to $20 \mathrm{~km}$ for the correction of all the flight lines. The results are in close agreement with the visibility $(20 \mathrm{~km})$ reported by the airport of Ostend.

Figure 6 shows the result of the atmospheric correction. In the green, red and NIR parts of the spectrum a good correspondence between the corrected airborne data and in-situ reflectance spectra is obtained. Seaborne reflectance measurements were performed by MUMM using TRIOS and SIMBADA spectrometers. Some differences in the absolute reflectance values can be due to the time difference between the in-situ measurements and the airborne data acquisition. Possible causes of the larger reflectance difference below $500 \mathrm{~nm}$ are inaccuracies in the sensor calibration (spectral calibration error visible around $430 \mathrm{~nm}$ ), in the atmospheric aerosol characterization (standard MODTRAN-4 models used) and/or errors in the skyglint due to sea roughness.

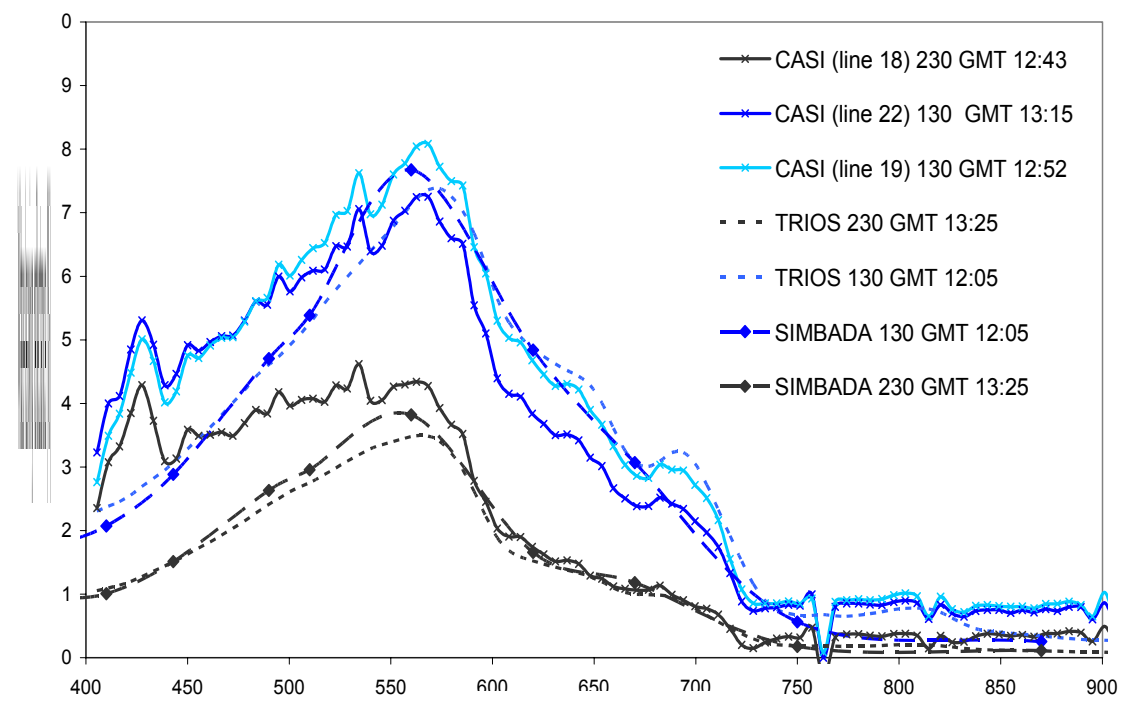

Figure 7: Comparison of water-leaving reflectance from CASI images, after the WATCOR correction, with in-situ measured spectra (130 and 230 are two measurement points). 


\section{Conclusions}

The applications presented above show that imaging spectroscopy is a valuable technique to address a variety of coastal and marine applications. The detailed spectral information can be used to gain knowledge on sediments, water quality and even submarine ecosystems like coral reefs. Applications on coastal sediments, e.g. beach erosion, are closely in line with other pedological and geological applications. However, the aquatic applications ask for specific data; in water red and NIR wavelengths are almost completely absorbed while the blue and to a lesser extent the green light is scattered. The water leaving reflectance is low and limited to these short wavelengths, therefore one needs spectrometers which are sensitive in the deep blue and green range. The airborne APEX sensor which is currently under development for ESA is one of the sensors that pay specific attention to the shorter wavelengths and will therefore be very suited for aquatic applications. Other problems to overcome are the atmospheric correction above water bodies, the air-water interface and the water-column correction (see Chapter 2.5). Despite these extra difficulties imaging spectroscopy has already proven its capability for water quality monitoring and the monitoring of submarine ecosystems.

\section{Acknowledgments}

The authors are grateful to the Belgian Science Policy who is financing all of the above mentioned projects except for the study on the sand transport processes along the Belgian coast. This study was financed by the Flemish Government Department Environment \& Infrastructure - Waterways and Marine Affairs Administration (AWZ) - Coastal Division (WWK), to whom we also express our thanks. The full paper in its original colour version is available as pay-perview on the WIT Press E-Library: http://library.witpress.com.

\section{References}

[1] Bertels, L., Knaeps, E., Sterckx, S., Deronde, B., Vanderstraete, T., Van Coillie, S. \& Goosens, R., Monitoring of coral reefs using hyperspectral data; A case study: Fordata, Tanimbar, Indonesiä, Coastal Environment and Oil Spill 2006. Wessex conference, 2006.

[2] Bryant, D., Burke, L., McManus, J. \& Spalding, M., Reefs at Risk - A Map-Based Indicator of Threats to the World's Coral Reefs. WRI, Washington (USA), p. 56, 1988.

[3] Cracknell, A.P., Remote sensing techniques in estuaries and coastal zones, an update. International Journal of Remote Sensing, 19(3): 485-496, 1999.

[4] Deronde, B., Houthuys, R., Debruyn, W., Fransaer, D., Van Lancker, V. \& Henriet, J.-P., In press. Using Airborne Hyperspectral Data and Laserscan Data to Study Beach Morphodynamics along the Belgian Coast. Journal of Coastal research. 
[5] Deronde, B., Kempeneers, P., Forster, R.M. \& Debruyn, W., submitted, Imaging spectroscopy as a tool to study sediment characteristics on a tidal sand bank in the Westerschelde. Estuarine Coastal and Shelf Science.

[6] Goetz, A.F.H., Principles of narrow band spectrometry in the visible and IR: instruments and data analysis. In: F. Toselli \& J. Bodechtel (eds.) Imaging spectroscopy: Fundamental and Prospective Applications, Dordrecht, Kluwer Academic Publishers, 21-32, 1992.

[7] Hedley, J.D. \& Mumby, P.J., A Remote Sensing Method for Resolving Depth and Subpixel Composition of Aquatic Benthos. Limnology \& Oceanography, 48 (1-2): 480-488, 2003.

[8] Keller, P., Imaging Spectroscopy of Lake Water Quality Parameters. PhD Thesis, Remote Sensing Series 36, RSL, University of Zurich, 2001.

[9] Kutser, T., Dekker, A.G. \& Skirving, W., Modeling Spectral Discrimination of Great Barrier Reef Benthic Communities by Remote Sensing Instruments. Limnology \& Oceanography, 48 (1-2): 497-510, 2003.

[10] Matthews, A.M., Duncan, A.G. \& Davison, R.G., Error assessment of validation techniques for estimating suspended particulate matter concentration from airborne multispectral imagery. Int. J. Remote. Sensing, 22(2\&3): 449-469, 2001.

[11] Mumby, P.J. \& Edwards, A.J., Mapping Marine Environments with IKONOS Imagery: Enhanced Spatial Resolution Can Deliver Greater Thematic Accuracy. Remote Sensing of Environment, 82 (2-3): 248-257, 2002.

[12] Spalding, M.D., Ravilious, C. \& Green, E.P., World Atlas of Coral Reefs. UNEP-WCMC, University of California Press, Berkeley (USA), p. 424, 2001.

[13] Sterckx, S. \& Debruyn, W., A hyperspectral view of the North Sea. In proceedings of Airborne Imaging Spectroscopy workshop, Bruges, 8 October 2004.

[14] Sterckx, S., Debruyn, W. \& Kempeneers, P., Hyperspectral airborne remote sensing of the Belgian Coastal Waters. Submitted to Proceedings of the 4the Workshop on Imaging Spectroscopy workshop (Earsel), Warsaw, April 2005. 